\title{
MOTIFS OF MANDANA ART IN FASHION PRODUCT
}

\section{Sangeeta Soni ${ }^{* 1} \mathbb{\square}$}

${ }^{* 1}$ Senior Lecturer Government Women's Polytechnic College, Bhopal, India

DOI: https://doi.org/10.29121/granthaalayah.v8.i8.2020.1032

\section{Article Type: Research Article}

Article Citation: Sangeeta Soni. (2020). MOTIFS OF MANDANA ART IN FASHION PRODUCT. International Journal of Research GRANTHAALAYAH, 8(8), 233-238. https://doi.org/10.29121/granthaa layah.v8.i8.2020.1032

Received Date: 09 August 2020

Accepted Date: 30 August 2020

Keywords:

Art

Mandana

Traditional

Culture

Running Stitch

Katha

Redesign

\section{ABSTRACT}

India have a rich Art and Culture heritage, Our cultural and Traditional art speaks about how sensible our Ancestors are, they have Beliefs and reasons behind every art and culture work they do or create. We have varieties of Art forms like painting, sculpture, pottery, and textile arts such as woven silk are one of our Rich Cultural Heritage which makes our India Incredible.

One of The Traditional Art is Mandana Art which i used in the redesigning of Mandana Motifs through painting on women's apparels and high light them by Traditional Embroidery -Kantha Work.

\section{INTRODUCTION}

\subsection{WHAT IS MANDANA ART?}

Mandana paintings are one of the oldest forms of tribal art in India that has survived over the ages. It is the art originated from Madhya Pradesh and Rajasthan which is made on walls and floors with Khariya (chalk solution) and Geru (red ochre).

Inspired from this Art I worked on a project where I created hand bags with beautiful motifs of Mandana art which is highlighted with Katha stitch (Running Stitch). The whole process reminds us the days when our mothers use to create this art on festival seasons to welcome gods as a mark of celebrations. 


\section{Designs of Mandana Art|}

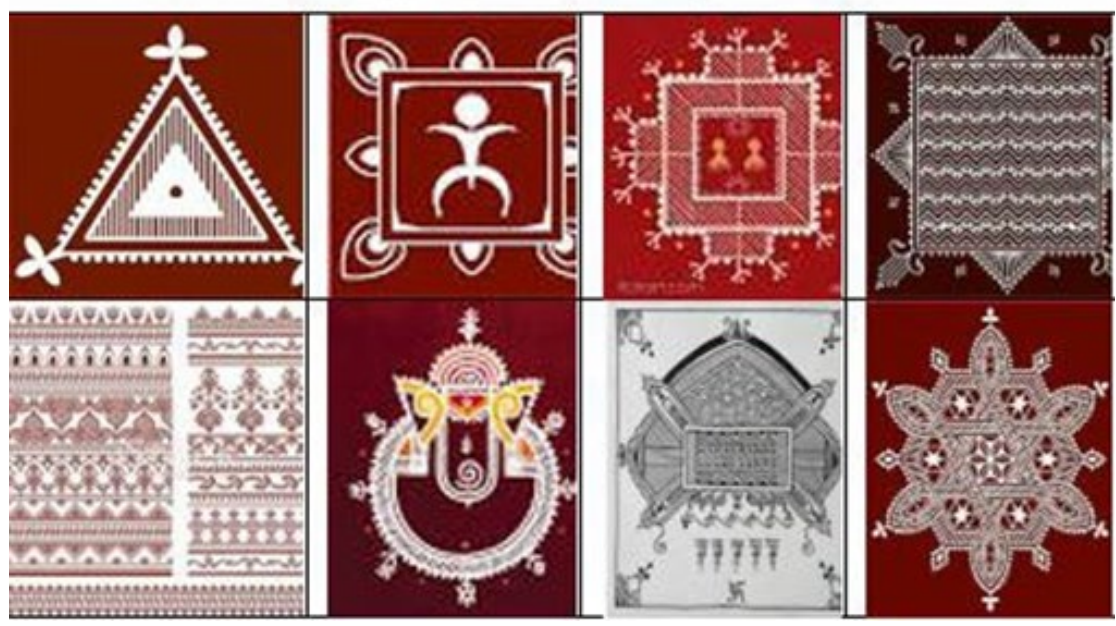

\section{PROCESS}

\subsection{SOURCE OF INSPIRATION}

The motifs of these paintings are inspired by beliefs that pertain to auspiciousness and good omens. The technical term for such motifs is Shubh Manglik. Many of the other patterns seen in the Mandana paintings are also reminiscent of the designs of the altars of Vedic Yagna, the vastu purasha mandalas and the floor plans of temples from the days of yore. There are many designs one sees in Mandana paintings that are directly influenced by architectural features as well as geometry.

\subsection{STUDY}

Size of Samples for survey: The size of sample is 100 to know the opinion of people about product.

Target Group: Targeted age group 35-45 (working women and housewives both).

Area of Survey: Approach the samples in Bhopal City.

Tools: Approach any individual through questionnaire for their acceptance of the product.

Method of sampling: Purposively sampling for 100 samples, having age group 35-45 years women's those who are working women and housewives both.

Design: Designs were developed considering the Mandana motifs through fabric painting technique and high lights them by Traditional Embroidery Kantha Work - Running stitch.

\subsection{SKETCHES}

4.1 - B) ROUGH SKETCHS OF TOE BAG
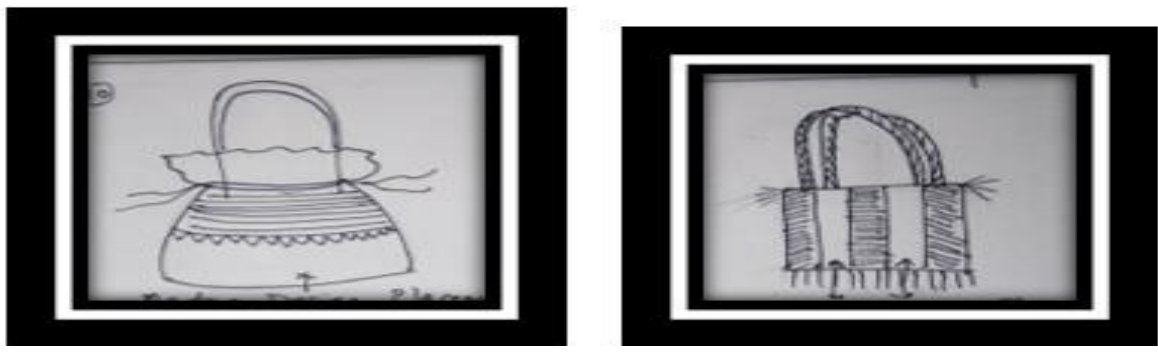


\section{SAMPLE PREPARING BY KANTHA WORK- RUNNING STITCH}
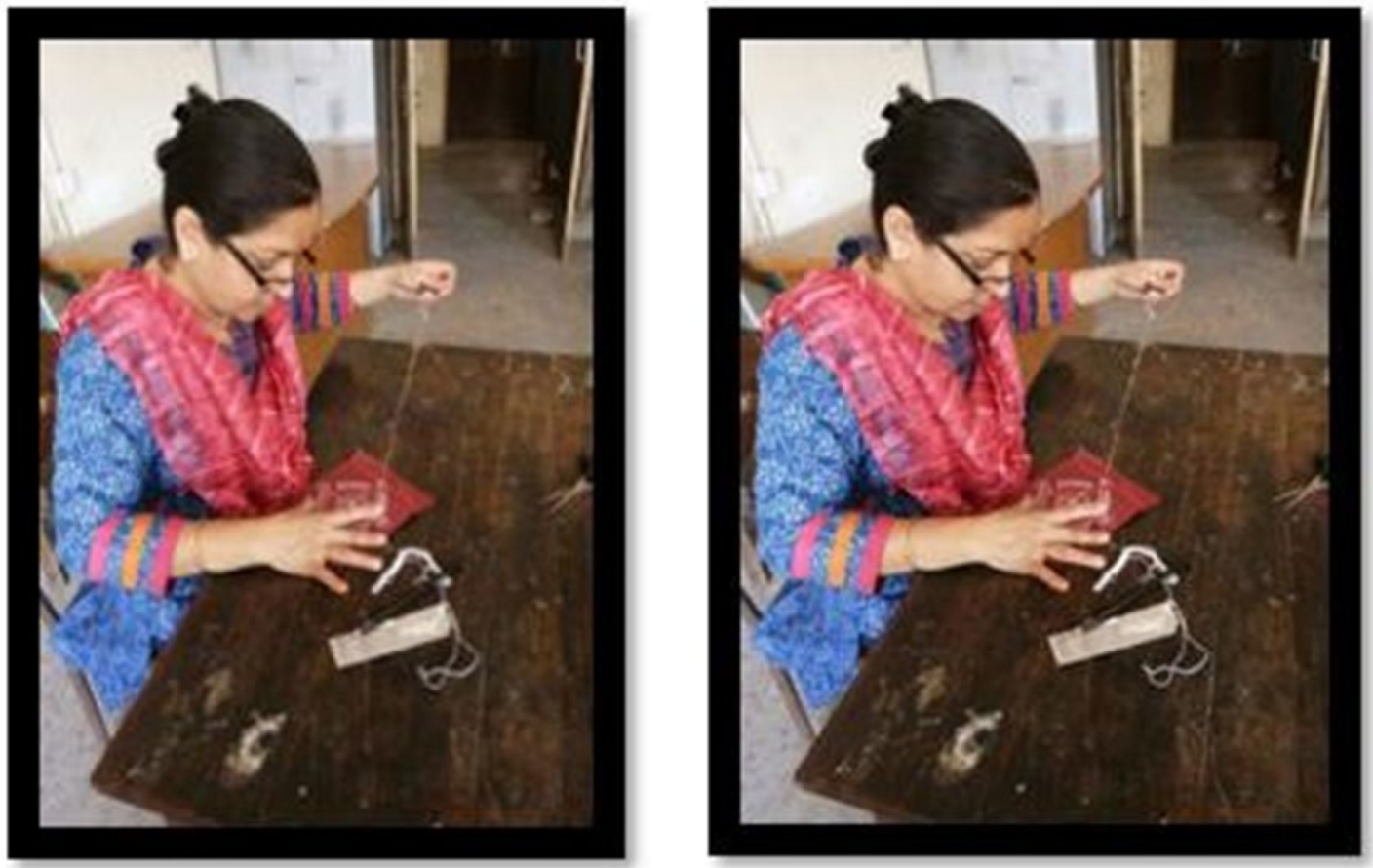

figure no 03 ij \& ii) Sample making by Kantha Work-Runing Stitch

\subsection{SURFACE ORIENTATION TECHNIQUES}

1) Fabric Painting - Acrylic paint are used which is a fast-drying paint made of pigment suspended in acrylic polymer emulsion. Acrylic paints are water-soluble, but become water-resistant when dry.

2) Katha Stitch- The Running Stitch, also referred to as Straight Stitch, is one of the basic hand sewing and embroidery technique on which most other forms of stitching and embroidery are based. The procedure for working the stitch involves inserting the needle into a fabric and taking it out at small intervals.
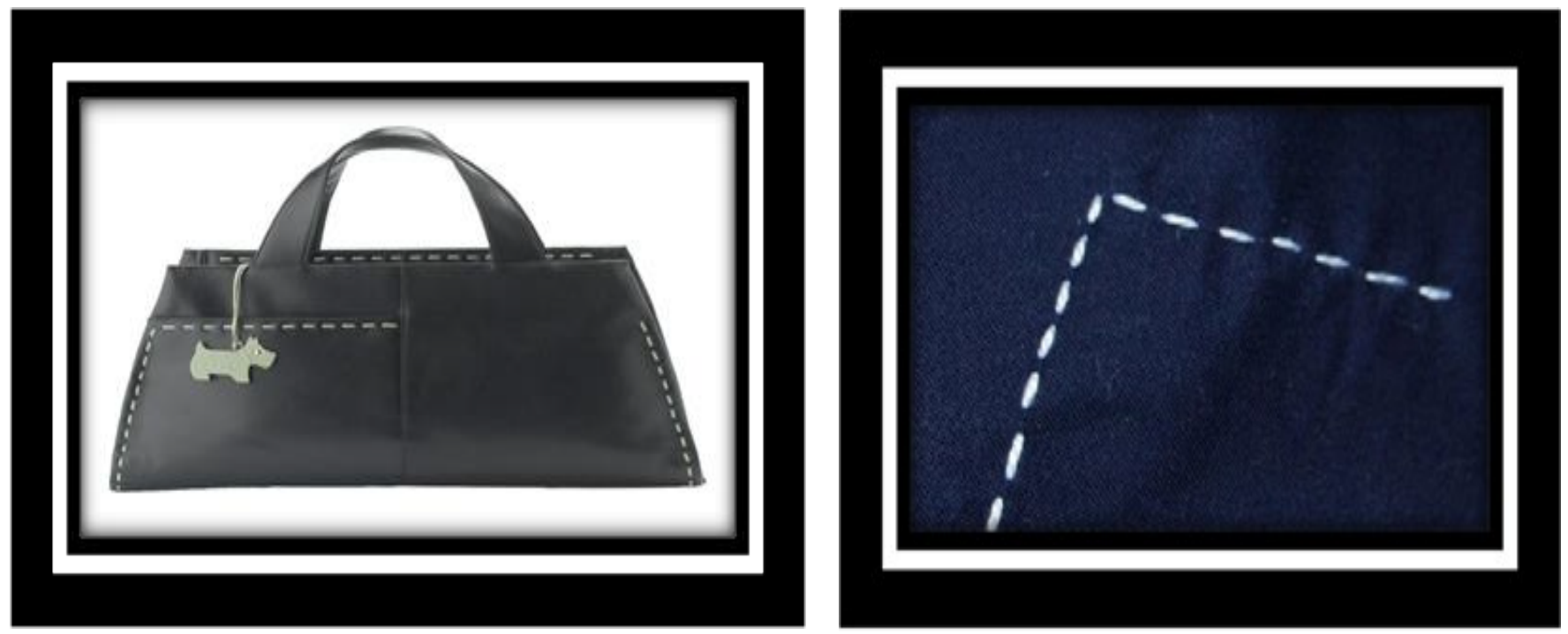
Motifs of Mandana Art in Fashion Product

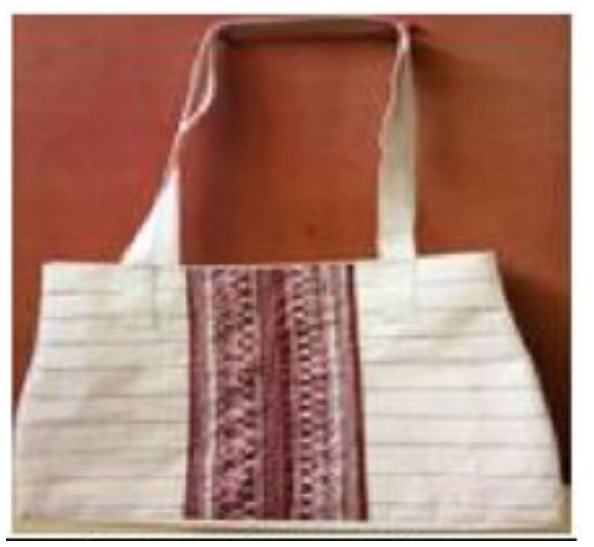

Design 1

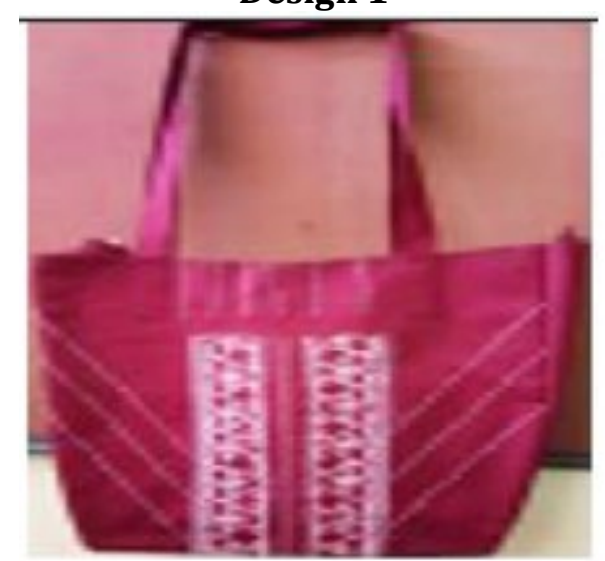

Design 4

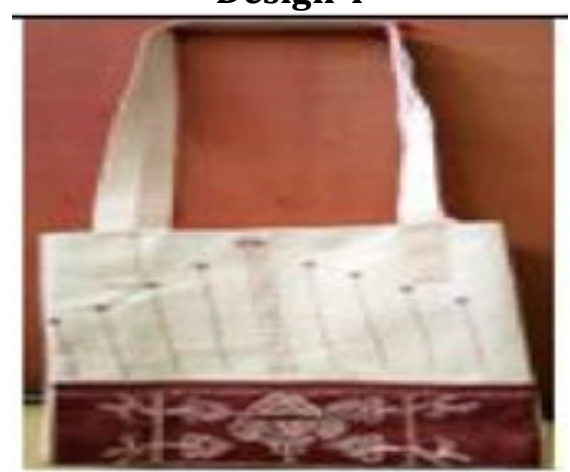

Design 7

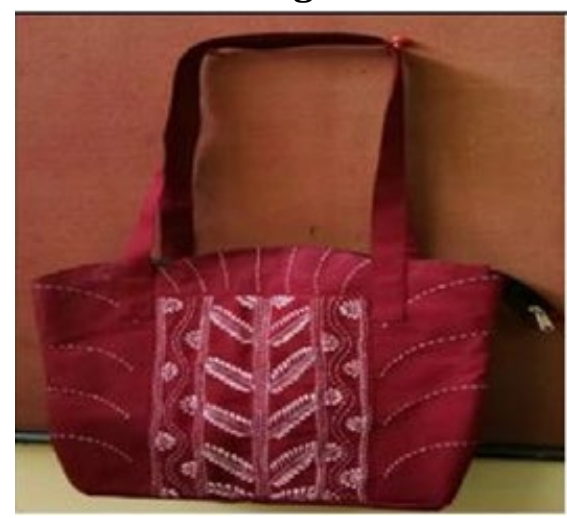

Design 10
FINAL PRODUCT - TOTE HAG

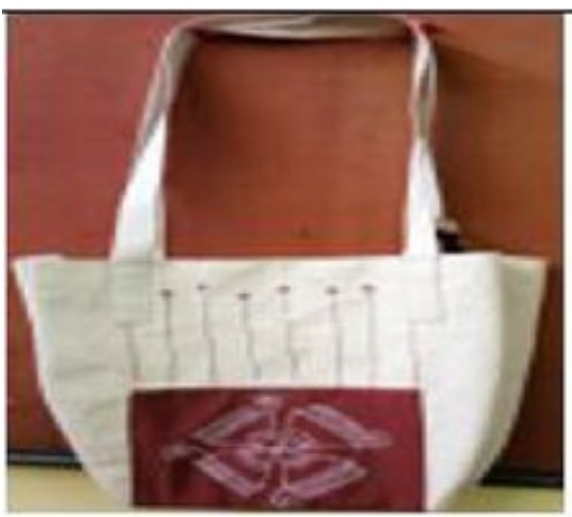

Design 2

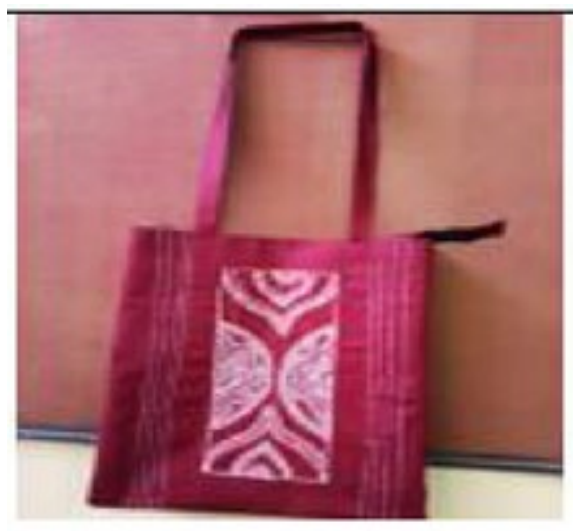

Design 5

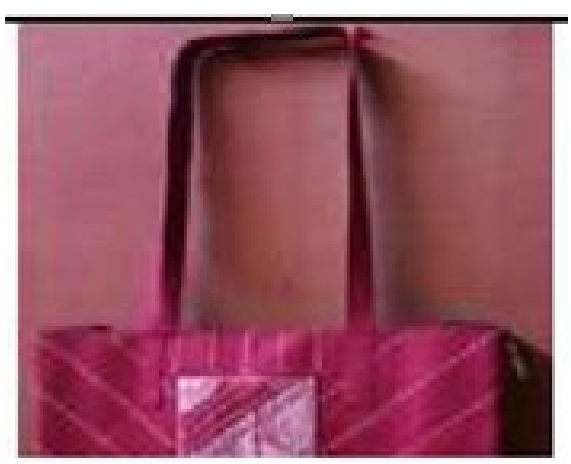

Design 8

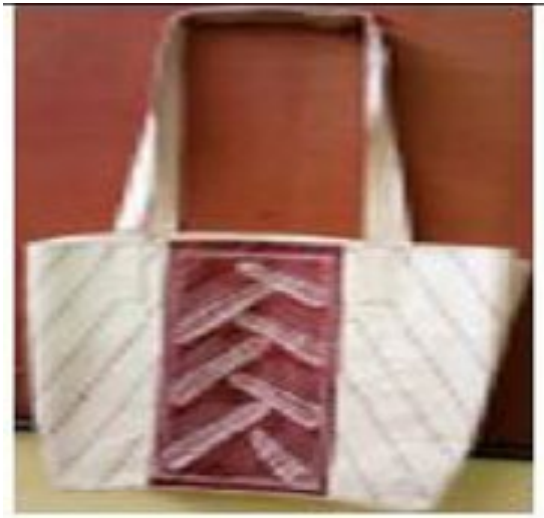

Design 3

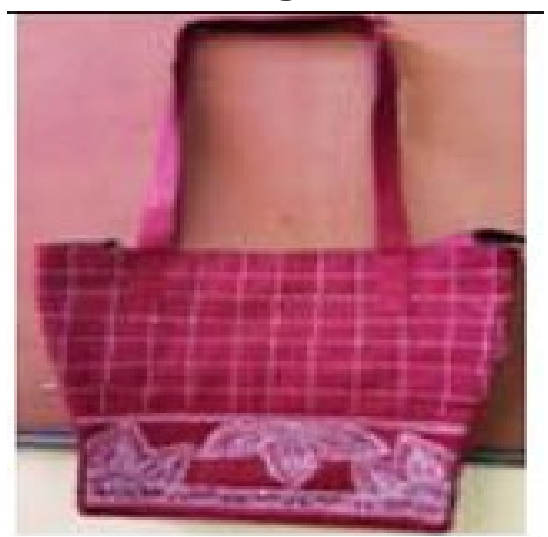

Design 6

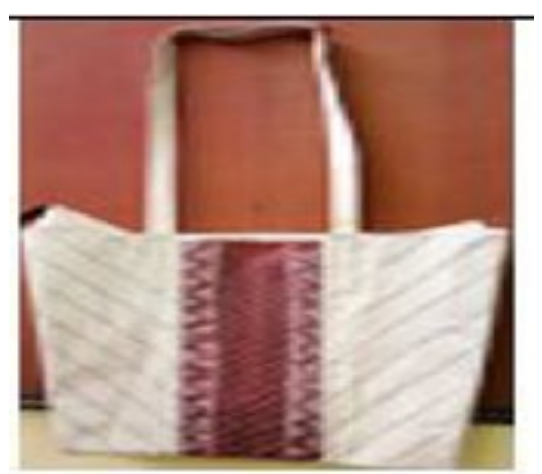

Design 9 


\section{SURVEY AND DATA ANALYSIS}

Out of 100 respondents 59 has given excellent rating ie.59\%.23 has given very good rating ie.23\% and rest 18 has given good rating. This explains that most of them find it excellent. They like the design adopted in innovated product

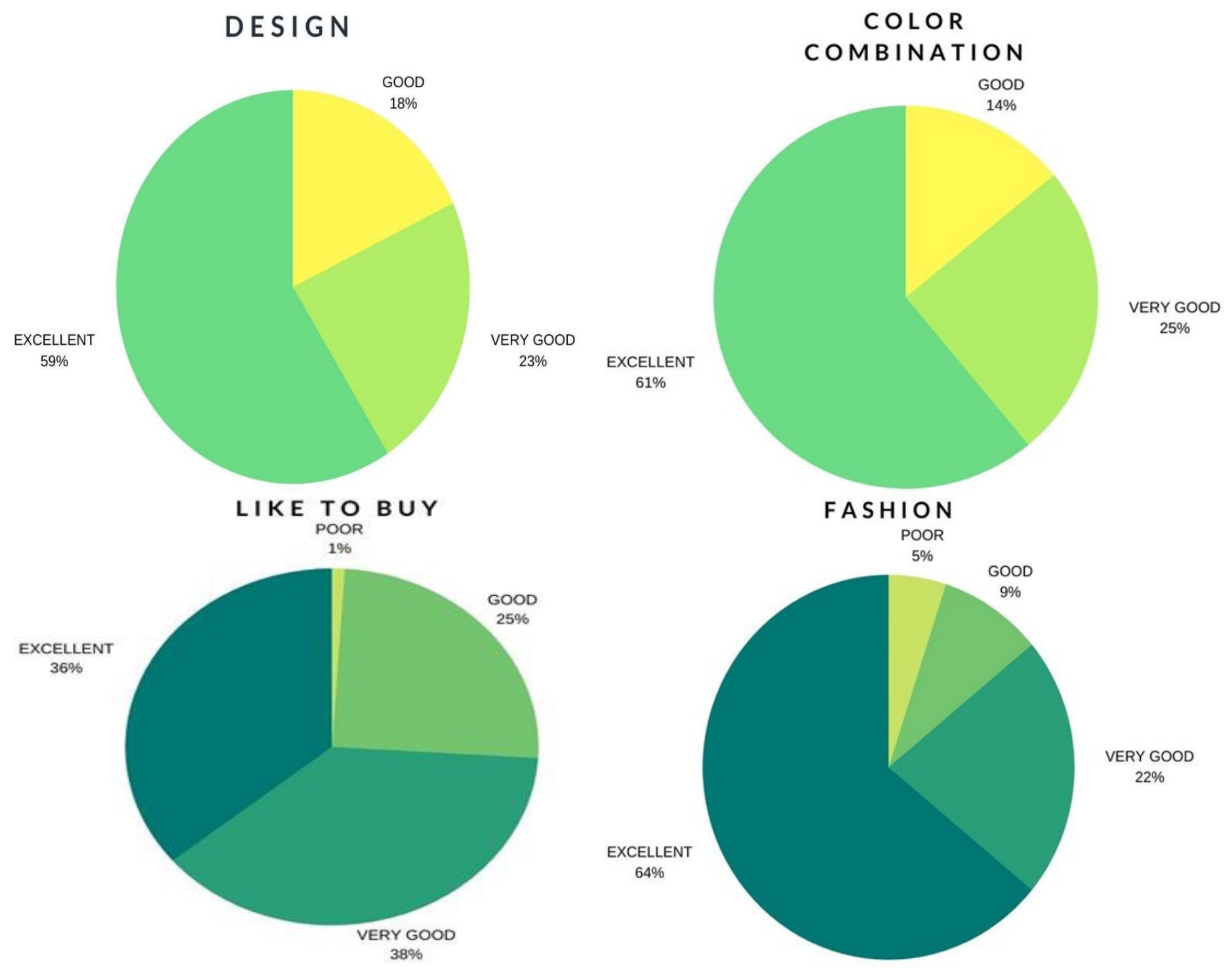

\subsection{PROMOTING SUSTAINABLE FASHION}

There are environmental concerns regarding use and disposal of plastic shopping and trash bags. It takes 1000 years to decompose plastic, which causes infertility of soil and cause pollution Sustainable Fashion is a way towards environmental health and it is our social responsibility to keep our environmental clean and pollution free,

Use of a cotton or natural fibre bag is the 1st step towards the sustainable fashion. Disposable bag can often be used many times, for economic and environmental reasons.

Conclusions- The purpose of the collection 'Redesign of Mandana Art motifs through Painting and Kantha Work on Apparels' was to find the need and acceptance of the product through the survey. The survey was conducted of the target group of 35 - 45 years Working Women and Housewives both as the product will be more accepted by them as they follow Sustainable fashion trends.

- According to the study majority of the people would prefer to redesign the Mandana motifs on Apparels.

- The reason being they look Classic; attractive motifs they are durable and are available at a good price.

International Journal of Research -GRANTHAALAYAH 
- People prefer to use Tote bags. They use handbags on casual basis.

- The most preferred type of bags is very new looking, fashionable and trendy bags,

\section{SOURCES OF FUNDING}

The Aim of this collection is to get inspired from our rich cultural heritage and use it creatively to save our cultural heritage from the drastic drop of its visibility. Products are the Fashion Accessories targeting 35-45 years women's.

\section{CONFLICT OF INTEREST}

The author have declared that no competing interests exist.

\section{ACKNOWLEDGMENT}

None.

\section{REFERENCES}

[1] www.pinterest.com

[2] https://en.wikipedia.org/wiki/Mandana_Paintings

[3] https://en.wikipedia.org/wiki/Kantha

[4] https://in.pinterest.com/artorok/mandana-art/

[5] https://in.pinterest.com/pin/107664247313376338/

[6] http://en.wikipedia.org/wiki/mandana_paintings

[7] https://www.utsavpedia.com/motifs-embroideries/mandana-paintings/ 